\title{
Traits and stress: keys to identify community effects of low levels of toxicants in test systems
}

\author{
Matthias Liess • Mikhail Beketov
}

Accepted: 15 April 2011/Published online: 27 April 2011

(C) The Author(s) 2011. This article is published with open access at Springerlink.com

\begin{abstract}
Community effects of low toxicant concentrations are obscured by a multitude of confounding factors. To resolve this issue for community test systems, we propose a trait-based approach to detect toxic effects. An experiment with outdoor stream mesocosms was established 2-years before contamination to allow the development of biotic interactions within the community. Following pulse contamination with the insecticide thiacloprid, communities were monitored for additional 2 years to observe long-term effects. Applying a priori ecotoxicological knowledge species were aggregated into trait-based groups that reflected stressor-specific vulnerability of populations to toxicant exposure. This reduces inter-replicate variation that is not related to toxicant effects and enables to better link exposure and effect. Species with low intrinsic sensitivity showed only transient effects at the highest thiacloprid concentration of $100 \mu \mathrm{g} / \mathrm{l}$. Sensitive multivoltine species showed transient effects at $3.3 \mu \mathrm{g} / \mathrm{l}$. Sensitive univoltine species were affected at $0.1 \mu \mathrm{g} / \mathrm{l}$ and did not recover during the year after contamination. Based on these results the new indicator $S P E A R_{\text {mesocosm }}$ was calculated as the relative abundance of sensitive univoltine taxa. Long-term community effects of thiacloprid were detected at concentrations 1,000 times below those detected by the PRC (Principal Response Curve) approach. We also found that those species, characterised by the most vulnerable trait combination, that were stressed were affected more strongly by thiacloprid than non-stressed species. We conclude that the grouping of species according to toxicant-related traits enables
\end{abstract}

M. Liess $(\bowtie) \cdot$ M. Beketov

Department System-Ecotoxicology, UFZ - Helmholtz Centre

for Environmental Research, Leipzig 04318, Germany

e-mail: matthias.liess@ufz.de identification and prediction of community response to low levels of toxicants and that additionally the environmental context determines species sensitivity to toxicants.

Keywords Risk assessment · Long-term effect · Low-level toxicant - Population stress - Trait indicator system $\cdot$ Habitat templet concept

\section{Introduction}

Effects of toxicants at high concentrations that induce a high rate of acute mortality are observed easily, even in complex communities. Prominent examples are the effects following catastrophes such as the pesticide spill from the chemical company Sandoz into the River Rhine (Van Urk et al. 1993) and the oil spill from the tanker Exxon Valdez (Peterson et al. 2003). The effects of toxicants at low concentrations that do not immediately result in acute mortality are much more difficult to detect. This is because, in such cases, communities are shaped not only by the effects of the toxicant but also to a great extend by other environmental factors. As a result, the complex relationship between a multitude of environmental factors and the composition of the community obscures the effects of the toxicants (Liess et al. 2008). Additionally, confounding factors may also mask the effects of toxicants. For example, pesticide runoff is often associated with increased hydrodynamic stress. Therefore, until recently the effects of pesticide runoff and of hydrodynamic stress were only distinguished using experimental approaches (Liess and Schulz 1999).

Trait-based approaches are a powerful tool that can be used to link habitat characteristics to life history strategies (Southwood 1988). On the basis of this approach, 
a posteriori associations between species traits and various environmental parameters have been identified over an extended geographical region (Usseglio-Polatera et al. 2000) (see also Doledec and Statzner 2008; Statzner and Beche 2010). Trait based approaches can also provide a priory predictions of species traits to be expected according to the environmental characteristics of a given habitat (Townsend and Hildrew 1994). Inversely, the occurrence of traits of species in a given habitat can be used to infer environmental characteristics. To identify the effects of agricultural pesticides on field communities this approach was first developed by Liess and co-workers (Liess et al. 2001) and later elaborated within the Species At Risk concept (SPEAR) (Liess and von der Ohe 2005). The SPEAR bioindicator system was validated to identify non-point pesticide contamination (Schäfer et al. 2007) and point sources of toxicants originating from treatment plants (Ashauer, in revision). The identification of trait combinations that were associated with a specific environmental parameter (stressor) enabled the effects of this parameter to be identified on the trait composition of the community, even though a multitude of other parameters were affecting the composition of taxa within the community.

Despite the considerable advances that these methods have yielded for field studies, trait-based methods have not been adopted for experimental studies at the community level (i.e. mesocosm tests) that support prospective risk assessment of toxicants (deJong et al. 2008). However, it has been shown clearly that life-cycle traits are of the utmost importance for predicting the dynamics of the effects of, and recovery from, toxicants in mesocosms (Sherratt et al. 1999; Beketov et al. 2008). The development of a trait-based index similar to the well-validated pesticide-specific index $S P E A R_{\text {pesticide }}$ is now required (Liess and von der Ohe 2005). Such an index will not only enable the stressor-specific assessment of effects and associated recovery, but will also allow the tested communities to be standardised according to ecologically relevant traits. This trait-based standardisation, in comparison with taxonomy-based standardisation, can be performed on large spatial scales and linked to ecosystem functions and services (McGill et al. 2006; Schäfer et al. 2007; Menezes et al. 2010; Peru and Doledec 2010).

The relationship between toxicant exposure and effect on individuals and populations is also determined by the environmental context. Indeed, stress conditions often increase the sensitivity of individuals to toxicants (see Heugens et al. 2001 for review). Hence, to determine the quantitative link between exposure and effect it is necessary to consider additional stress factors. Such factors include a wide range of stressors that increase the rate of mortality due to toxicants (factor of increase in brackets): exalted temperature (10) (Song et al. 1997), food limitation (2) (Pieters et al. 2005), exalted salinity (10) (Wildgust and Jones 1998), low oxygen (2) (Van der Geest et al. 2002), UV radiation (30) (Liess et al. 2001), competition (10) (Liess 2002), predation (8) (Beketov and Liess 2006), and the requirement of food acquisition (10) (Mommaerts et al. 2010).

The aim of the study reported herein was to explore the possibility that exposure to a low level of toxicants exerts a strong and sustained effect on the composition of a community and to identify methods with which to link exposure to low levels of toxicants and community response. For this purpose, we developed a new trait-based index, $S P E A R_{\text {mesocosm }}$, which was based on the $S P E A R_{\text {pesticide }}$ index designed for bioassessment of pesticide contamination in the field (Liess and von der Ohe 2005). To achieve this aim, we performed and evaluated a long-term 4-year experiment with an outdoor stream mesocosm system that was designed to mimic small streams in agricultural landscapes.

\section{Methods}

\section{Mesocosm system}

The mesocosm system consisted of 16 artificial streams that were characterised by the following parameters: length $20 \mathrm{~m}$, width at water surface $0.32 \mathrm{~m}( \pm 0.03)$, average depth $0.25 \mathrm{~m}( \pm 0.11)$, discharge $160 \mathrm{l} / \mathrm{min}( \pm 9)$, slope $2 \%$, and approximate total volume of 1,000 1 . Each stream was designed as a closed circulation system with the following flow of water. From the upstream to the downstream sections of the stream, the water was propelled by gravity. It then reached a 200-1 reservoir installed below the downstream margin of the stream. Subsequently, it was pumped back to the upstream section through a plastic tube by an electric pump. Loss of water through evaporation was compensated for by rain- and tap water. A dam with a polyester net filter (1-mm mesh) was installed at the end of each stream to prevent the loss of animals through drift. The stream channels were situated in the ground to a depth of approximately $0.4 \mathrm{~m}$ and lined with watertight non-toxic polyvinylchloride foil. The bottom of each stream was covered with a mixture of fine gravel and sand (particle size $0.2-3.7 \mathrm{~mm}$, layer depth of $30-50 \mathrm{~mm}$ ) and half of the bottom surface in the cross-channel direction was planted with watercress (Nasturtium officinale). An area of ground was retained between the streams to support riparian vegetation, in order to provide a refuge for insects that emerged, reduce the amount of direct sunlight, and in general to create an ecology that matches that found in small lowland streams as much as possible. 
Table 1 Main physico-chemical parameters of water in the stream mesocosms

\begin{tabular}{lcc}
\hline Parameter & Mean & Standard deviation \\
\hline Ammonium $(\mathrm{mg} / \mathrm{l})$ & 0.061 & 0.23 \\
Nitrate $(\mathrm{mg} / \mathrm{l})$ & 4.12 & 7.44 \\
Nitrite $(\mathrm{mg} / \mathrm{l})$ & 0.005 & 0.02 \\
Phosphate $(\mathrm{mg} / \mathrm{l})$ & 0.18 & 0.24 \\
Hardness $(\mathrm{mg} \mathrm{Ca} / \mathrm{l})$ & 53.22 & 3.01 \\
Dissolved oxygen $(\%)$ & 93.2 & 15.9 \\
pH & 7.75 & 0.19 \\
Conductivity $(\mu \mathrm{S} / \mathrm{cm})$ & 464 & 87.3 \\
\hline
\end{tabular}

The main physico-chemical parameters of the water were measured every 4 months (Table 1 ). Concentrations of ammonium, nitrite, nitrate, phosphate, and total hardness were determined with Aquamerck colorimetric tests (Merck, Darmstadt, Germany). Conductivity, dissolved oxygen, and $\mathrm{pH}$ were measured with LF330, OXI 340, and Multi 340i electronic meters respectively (WTW, Weilheim, Germany). No significant differences between the groups of treatment and control streams were found concerning the physico-chemical parameters $(P>0.05$, analysed for every measuring date with multivariate analysis of variance (MANOVA)). Values of water quality parameters were well in a range considered not to have any negative impact on macroinvertebrates present in the mesocosms. Especially Nitrate and Ammonium that may cause problems in closed systems were far below harmful concentrations (Berenzen et al. 2001).

Monitoring of long-term development of temperature was done by measuring constantly (every $3 \mathrm{~h}$ ) with $\mu \mathrm{S}-L O G 540$ data logger (Driessen + Kern, Bad Bramstedt, Germany) in two randomly selected streams. The maximum summer (April to September) and minimum winter (October to March) temperatures were 24.8 and $2.9^{\circ} \mathrm{C}$ respectively. Mean summer and winter temperatures were 20.1 and $4.7^{\circ} \mathrm{C}$ respectively. Comparison of temperature regimes between all streams was done by constantly (every $3 \mathrm{~h}$ ) temperature with data loggers (Driesen + Kern, Bad Bramstedt, Germany) in each stream for 1 month (02-30.03.2007). No significant differences between the groups of treatment and control streams were found for mean, maximum, and minimum temperatures $(P>0.05$, univariate analysis of variance (ANOVA)).

\section{Experimental schedule and design}

The entire experimental period was 4 years and 3 months; from September 2003 to December 2007. The mesocosm system was constructed in the summer of 2003. The streams were planted with macrophytes in September 2003 and colonised by macroinvertebrates during the winter of 2003-2004 and in October 2005 by adding sediments and macroinvertebrates collected in an uncontaminated stream located near the city of Grimma in Germany.

The streams were contaminated with the insecticide thiacloprid in May 2006 and May 2007. The experimental design included 16 independent streams and four treatment levels (control, $0.1,3.2$, and $100 \mu \mathrm{g} / \mathrm{l}$ thiacloprid) with two replicates for each concentration level and 10 replicates for the control in 2006 and four replicates for each concentration level including the control in 2007. The streams that were contaminated at a certain concentration in 2006 were contaminated with the same concentration in 2007. For the second contamination (2007), two replicates for each concentration level were reallocated from the streams used as controls in 2006. A 2-year precontamination period was employed to establish a community with strong biotic interactions (competition, predation) and a considerable number of sensitive and long-living taxa. At the beginning of the experiment 16 out of 35 species were considered as sensitive according to the SPEAR classification (Liess and von der Ohe 2005); from these 16 sensitive species 5 species were univoltine.

\section{Thiacloprid application and monitoring}

Thiacloprid (generic name (CA) [3-[(6-chloro-3-pyridinyl) methyl]-2-thiazolidinylidene] cyanamide, CAS number 111988-49-9) is a neonicotinoid insecticide. Among neonicotinoids, it is used against various chewing and sucking pests. Thiacloprid was obtained from Agrar-Handel und Transport (Schafstädt, Germany) as the commercial formulation Calypso (suspension concentrate), which contains $480 \mathrm{~g} / \mathrm{l}$ of the active ingredient (Bayer CropScience, Langerfeld, Germany). The initial nominal pulse concentrations for the three treatment levels (low, medium, and high) were $0.1,3.2$, and $100 \mu \mathrm{g} / \mathrm{l}$, respectively, in terms of the active ingredient. Throughout the paper, we refer to these nominal concentrations.

One litre of stock solution was prepared for each channel at the respective concentration by diluting the toxicant formulation with distilled water. The stock solutions were poured into the water reservoirs installed below the streams (see above for a description of the mesocosm system) to dilute the toxicant and make its input gradual. This was designed to simulate short-term contamination due to spray drift and surface water runoff, which constitute a relevant input path for small streams in agricultural areas (Liess et al. 1999). Aqueous solutions were applied because thiacloprid is highly soluble in water (the water solubility and $\log$ octanol-water partition coefficient (log $\mathrm{K}_{\mathrm{OW}}$ ) of the active ingredient at $20^{\circ} \mathrm{C}$ are $185 \mathrm{mg} / \mathrm{l}$ and 1.26, respectively; USEPA (2003)). 
Table 2 Analysis of thiacloprid residue

\begin{tabular}{llll}
\hline $\begin{array}{l}\text { Time after } \\
\text { contamination }(\mathrm{h})\end{array}$ & \multicolumn{2}{l}{ Mean measured concentrations \pm standard deviation at different time-points after contamination $(\mu \mathrm{g} / \mathrm{l})$} \\
\cline { 2 - 3 } & \multicolumn{2}{l}{ Nominal concentration $(\mu \mathrm{g} / \mathrm{l})$} & 100 \\
\cline { 2 - 3 } & 0.1 & 3.2 & $36.64 \pm 10.37$ \\
\hline First-year contamination $(n=4)^{\mathrm{a}}$ & $3.55 \pm 2.80$ & $6.48 \pm 1.43$ \\
48 & $\mathrm{NM}$ & $1.29 \pm 1.61^{\mathrm{b}}$ & $5.43 \pm 0.75^{\mathrm{b}}$ \\
120 & $\mathrm{NM}$ & $\mathrm{NM}$ & $76.33 \pm 10.03^{\mathrm{d}}$ \\
264 & $\mathrm{NM}$ & & $65.67 \pm 11.91^{\mathrm{d}}$ \\
Second-year contamination $(n=8)^{\mathrm{c}}$ & $2.64 \pm 0.21$ & $32.62 \pm 9.88$ \\
4 & $0.07 \pm 0.05$ & $\mathrm{NM}$ & $9.23 \pm 7.08$ \\
10 & $\mathrm{NM}$ & $0.48 \pm 0.54$ & $2.52 \pm 3.61$ \\
48 & $0.04 \pm 0.01$ & $0.23 \pm 0.20$ & $0.36 \pm 0.53$ \\
120 & $0.02 \pm 0.01$ & $0.07 \pm 0.05$ & $0.08 \pm 0.12$ \\
216 & $0.02 \pm 0.02^{\mathrm{e}}$ & $<0.01$ & $<0.01$ \\
312 & $<0.01^{\mathrm{e}}$ & $<0.01$ & \\
480 & $<0.01^{\mathrm{e}}$ & $\mathrm{NM}$ & \\
648 & $\mathrm{NM}$ & & \\
\hline
\end{tabular}

$N M$ not measured

${ }^{\text {a }}$ Two samples from each of the two channels

b $n=2$

c Two samples from each of the four channels

${ }^{\mathrm{d}} n=6$, two out of four streams were sampled with three samples each

e $n=4$, one sample from each of the four channels

Exposure to thiacloprid was monitored in the streams using spot water samples (Table 2). Two 200-ml samples were taken per each channel (in up- and downstream sections, non-vegetated areas) that resulted in four samples per each concentration (except the sampling of the channels treated at $100 \mu \mathrm{g} / \mathrm{l}$ performed $264 \mathrm{~h}$ after contamination). The samples were solid-phase-extracted immediately after sampling using $6 \mathrm{ml}$ Chromabond Easy columns (Macherey-Nagel, Düren, Germany) preconditioned with $6 \mathrm{ml}$ methanol. The columns were eluted with $12 \mathrm{ml}$ acetonitrile-ethylacetate $(1: 1 \mathrm{v} / \mathrm{v})$ and gently evaporated to $300 \mu \mathrm{l}$ under nitrogen. Analytical recovery was $82 \%$ with $18 \%$ standard deviation $(n=3)$ for $200 \mathrm{ml}$ of spiked water samples. All solvents used were of HPLC-grade and obtained from Merck KGaA (Darmstadt, Germany). All analyses were conducted by high-performance liquid chromatography (Agilent 1,100 series, Agilent Technologies Germany, Boeblingen, Germany) using a XDB-C18 column $(150 \times 2.1$ i.d., Agilent Technologies) and an Agilent 1,100 liquid chromatograph/mass selective detector (LC/MSD) for quantification. The limit of detection (LOD) for the concentration in the water phase was $0.03 \mu \mathrm{g} / \mathrm{l}$. A detailed description of the method can be found in Schäfer et al. (2008).
Macroinvertebrate sampling and processing

Macroinvertebrate sampling was done at the following time periods with respect to the contamination event, first year: $-34,-8,-4,-1,1,3,10,17$, and 27 weeks; second year: $-8,-4,-1,1,3,10$, and 27 weeks. Samples were obtained using a metal frame that covered a $15 \times 15 \mathrm{~cm}$ area of the bottom of the stream. This frame was shaped square, had 20-cm-high walls and a $15 \mathrm{~cm} \times 15 \mathrm{~cm}$ opening at the top and the bottom. For sampling, all macrophytes were removed from the enclosed area by hand, washed, and checked for macroinvertebrates in a white plastic tray. Subsequently, the water column was sieved and sediments were collected using a small hand net $(60 \times 55 \mathrm{~mm}$ frame, $500 \mu \mathrm{m} \mathrm{mesh})$ and examined for macroinvertebrates in the white tray. During each sampling, four samples in total were taken from each experimental channel: one from the upstream section, one from the middle upstream, one from the middle downstream, and one from the downstream section. Benthic samples were taken near the bottom of the channel, which included both macrophytes and non-vegetated substrate.

Macroinvertebrates were identified and counted in situ and returned to the stream with the exception of the very first sampling, which was undertaken in September 2005. 
For this first sampling, all the macroinvertebrates were preserved in $90 \%$ ethanol and identified in the laboratory. During subsequent samplings, this procedure was repeated when required (e.g. when new species were found that could not be identified in situ). Most of the Ephemeroptera, Odonata, Plecoptera, Trichoptera, Heteroptera, Coleoptera, Isopoda, and Amphipoda were identified to the species level, whereas for all other taxonomic groups, the level of identification varied from species to family. Oligochaeta were identified at the class level only.

Trait-based grouping of the macroinvertebrate taxa and the new index SPEAR $R_{\text {mesocosm }}$

To understand the dynamics of the effects of toxicants on species characterised by different biological traits, we divided the taxa into four groups using two traits: toxicological sensitivity to pesticides and generation time (in this study, this is defined in terms of voltinism) according to the SPEAR approach (Liess and von der Ohe 2005). On the basis of these binary divisions, we established the following four groups: (i) non-sensitive multivoltine, (ii) nonsensitive univoltine, (iii) sensitive multivoltine, and (iv) sensitive univoltine (see Appendix, Table 4). The classification of taxa with regard to toxicological sensitivity was based on the relative sensitivity distribution approach developed by Wogram and Liess (Wogram and Liess 2001) and revised by Von der Ohe and Liess (2004). Taxonspecific sensitivity values $\left(S_{\text {organic }}\right)$ were taken from the SPEAR Database (http://www.systemecology.eu/SPEAR/ index.php), and the threshold for dividing the taxa into sensitive and non-sensitive classes was taken from the

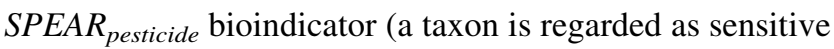
if it has an $\mathrm{S}_{\text {organic }}$ value $>-0.36$ (Liess and von der Ohe 2005). In addition, because thiacloprid is a neonicotinoid insecticide and has very unusual insect-specificity, this classification was based on detailed existing toxicological data. In detail the caddisfly species Hydropsyche angustipennis was considered to be sensitive, because Hydropsychidae has been shown to be sensitive to neonicotinoids (Yokoyama et al. 2009), despite the relatively low $S_{\text {organic }}$ value assigned to this group previously (von der Ohe and Liess 2004). Second, Ischnura elegans was grouped as insensitive as available information on Odonata suggest that the group is insensitive to thiacloprid (Beketov and Liess 2008). Hence, the general classification of taxon sensitivity was adapted for two species to produce a ranking of taxon sensitivity to this specific toxicant according to the available knowledge. In addition, taxa that did not exhibit aquatic stages during the contamination period, and were thus not present during the pesticide exposure, were not considered to be sensitive despite their toxicological sensitivity (Notidobia ciliaris, Appendix, Table 4).
As reflected in the names of the groups, the classification of taxa with regard to voltinism was based on the separation of taxa that have several generations per year (multivoltine) from those that have one or fewer generations per year (univoltine and semivoltine). For simplicity, we have used the term "univoltine" for the latter, because there was only one semivoltine species, Ephemera vulgata. The threshold value of 1 year was selected to match the frequency of contamination (annual) with the life cycles of the taxa and their respective abilities to recover, taking into account the proximity of the control and contaminated streams, which was necessary because insects that emerged from a control stream could easily oviposit in a contaminated stream and substantially facilitate recovery.

The new index $S P E A R_{\text {mesocosm }}$ was designed on the basis of the index SPEAR pesticide, which was developed to detect and quantify the effects of pesticides in the field (Liess et al. 2001; Liess and von der Ohe 2005; Liess et al. 2008); see also http://www.systemecology.eu/SPEAR/index.php). $S P E A R_{\text {mesocosm }}$ was based on the dichotomic classification of taxa into "species at risk" and "species not at risk" (this can refer to any taxonomic category, e.g. genus, family etc.) in accordance with the following three biological traits: toxicological sensitivity to organic toxicant ( $\mathrm{S}_{\text {organic }}$, which includes a substance-specific ranking based on available information, see above), generation time, and the presence of aquatic stages during contamination. A taxon is regarded as a "species at risk" only if it exhibits the following: (i) $\mathrm{S}_{\text {organic }}$ value $>-0.36$, (ii) generation time $\geq 1$ year, and (iii) aquatic stages that are unable to avoid exposure to pesticides. The differences from the

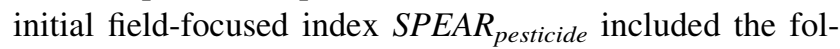
lowing: (a) a higher threshold for generation time ( $\geq 1$ year instead of $\geq 0.5$ year) and (b) the trait "migration ability" was not used. The rationale for using a higher threshold for generation time was the proximity of the control and contaminated streams and the associated high possibility of recovery through aerial migration. The trait "migration ability" from the SPEAR pesticide index was not used because it reflects in-stream (e.g. drift) migration and recolonisation from upstream sections; hence, it is irrelevant for a mesocosm system with closed circulation. The taxon-specific biological traits were taken from the SPEAR database (for the region Central Europe). The $S P E A R_{\text {mesocosm }}$ index was computed as the relative abundance of sensitive univoltine species, similarly to the earlier index $S P E A R_{\text {pesticide }}$ as detailed in the following formula:

SPEAR $_{\text {mesocosm }}=\frac{\sum_{i=1}^{n} \log \left(x_{i}+1\right) * y_{i}}{\sum_{i=1}^{n} \log \left(x_{i}+1\right)} * 100$

where $x_{i}$ is the abundance of taxon $i, n$ is the total number of taxa in the sample and $y_{i}$ is 1 if taxon $i$ is classified as sensitive, else 0. 
Data analyses

Data from separate samples taken from the same stream at a particular time point were pooled to avoid spatial pseudoreplication. To reduce the stochastic variability, data from successive time points were pooled pairwise. To give a traditional overview of the effect of thiacloprid on the macroinvertebrate communities, the widely employed univariate parameter $\mathrm{s}$ of abundance and taxa richness were used. Abundance was calculated as the $\log (\mathrm{x}+1)$ transformed number of individuals per square metre. Taxa richness was calculated as the number of taxa (species or other lowest possible taxonomic category) per sample.

To test for the significance of the effects of the toxicant on the univariate parameters (overall abundance, taxa richness, abundance of the four trait-based groups, and $S P E A R_{\text {mesocosm }}$ ), we used ANOVA followed by the Games-Howell post hoc test. The latter test is robust with respect to potential deviations from normality or variance homogeneity and exhibits a good type I error rate (i.e. a low probability of finding a difference between identical populations) and good power properties (Zar 1996). This conservative test was applied to confirm statistical significances, taking into account the low number of replicates. This method was used to infer the lowest- and no-observed-effect concentrations (LOEC and NOEC, respectively) on the basis of the $\mathrm{SPEAR}_{\text {mesocosm }}$ index. LOEC is defined here as the lowest concentration of toxicant at which a significant difference from the control is detected. Similarly, NOEC is defined as the highest concentration at which the effect is insignificant.

To compare the trait-based groups and SPEAR $R_{\text {mesocosm }}$ index with traditional methods of mesocosm data analysis, we employed the principal response curve (PRC) method and a set of redundancy analyses (RDA), which were performed for the different sampling time points (data $\log (\mathrm{x}+1)$-transformed). The PRC method is a multivariate technique developed especially to analyse data obtained in experimental studies on the responses of communities. It is based on the RDA ordination technique, which is a constrained form of principal component analysis (Van den Brink and Ter Braak 1999). The statistical significance of the PRC models, in terms of the displayed treatment variance, was tested by Monte Carlo permutation tests that were performed for the entire time series in the RDAs from which the PRCs were obtained, using an $F$-type test statistic based on the eigenvalue of the components (Van den Brink and Ter Braak 1999; Leps and Smilauer 2003). RDAs in which toxicant concentration $(\log (\mathrm{x}+1)$ transformed) was used as only one explanatory variable were applied in order to test the statistical significance of the effects of the toxicant on community structure at different concentrations of toxicants and different time points using the Monte Carlo permutation test, and therefore to infer the LOEC and NOEC. The latter type of test was performed by testing every concentration level against the control.

The grouping of the species on the basis of the traits selected for SPEAR $R_{\text {mesocosm }}$ was expected to reduce the variability in the effect endpoints both over time and between replicates. To identify such a reduction of variability for a trait based group compared to individual species we calculated the variability for abundance of each species building up this group, and the variability for the trait groups of species. We then compared the coefficients of variation $(\mathrm{CV})$ for individual species and trait groups. The comparison was based on the entire experimental period (4 years) for each experimental treatment separately (control and the three thiacloprid concentrations, all replicates pooled).

To analyse the relationships between species sensitivity, population stress, and viability, we first analysed the dynamics of the species that comprised the most sensitive group, "sensitive univoltine", in the control streams over the period of two summer seasons (May-November) after the first contamination. Specifically, between year changes (growth or decline) in abundance were quantified as a multiplication factor of the abundance in the first year (e.g. a factor of 2 would indicate doubling of the abundance from the first year to the second). Then, these changes in the abundance of species in the control streams were correlated with the abundance of the same species (average abundance over the same observation period of two seasons) in the streams exposed to the low concentration treatment $(0.1 \mu \mathrm{g} / \mathrm{l})$. This analysis revealed the presence of two distinct groups that were based on the population dynamics in the control: species that exhibited a decline or an increase in number. Therefore, instead of a regression model, we applied the one-sample $t$-test. This test was performed with predefined values of 0 and 100 to compare the observed values between the different groups of species and the control. This analysis was performed for the low concentration treatment only, because most of the sensitive univoltine species were eliminated completely at the higher concentrations. Furthermore, it was carried out only for the sensitive univoltine group, because the other groups of species experienced only transient effects and were able to recover shortly after contamination. Therefore, the analysis of long-term effects in relation to long-term population dynamics was not applicable for these groups.

Statistical analyses were performed using the following programs: R, version 2.7 for Mac OS $\times$ (http://www. r-project.org/), SPSS 11.0 for Mac OS $\times$ (SPSS Inc., Chicago, Illinois), and CANOCO 4.5 for Windows (Wageningen, Netherlands).

In all analyses, recovery was defined as the point when statistical tests failed for the first time to detect a significant 
difference between contaminated and control mesocosms, with the condition that a significant effect was not detected later (before the second contamination or until the end of the observation period).

\section{Results}

Abundance and taxa richness

A total of 42 macroinvertebrate taxa were identified in the mesocosm system (Appendix, Table 4). Out of these taxa, 35 were found in more than two streams and on more than one occasion, and were considered for the analyses reported below. Insects were the most diverse group and consisted of 24 taxa (not including rare taxa). The effect of thiacloprid on the total abundance was only detectable during a few weeks after contamination at the highest tested concentration of $100 \mu \mathrm{g} / \mathrm{l}$ (Fig. 1a). Also taxa richness was also only reduced shortly after contamination at the medium $(3.2 \mu \mathrm{g} / \mathrm{l})$ and high $(100 \mu \mathrm{g} / \mathrm{l})$ concentrations (Fig. 1b).

Trait-based groups of aquatic macroinvertebrates

The magnitude of the toxicant effect and the duration of recovery are linked strongly to the toxicological sensitivity and generation time of species. The grouping of taxa on the
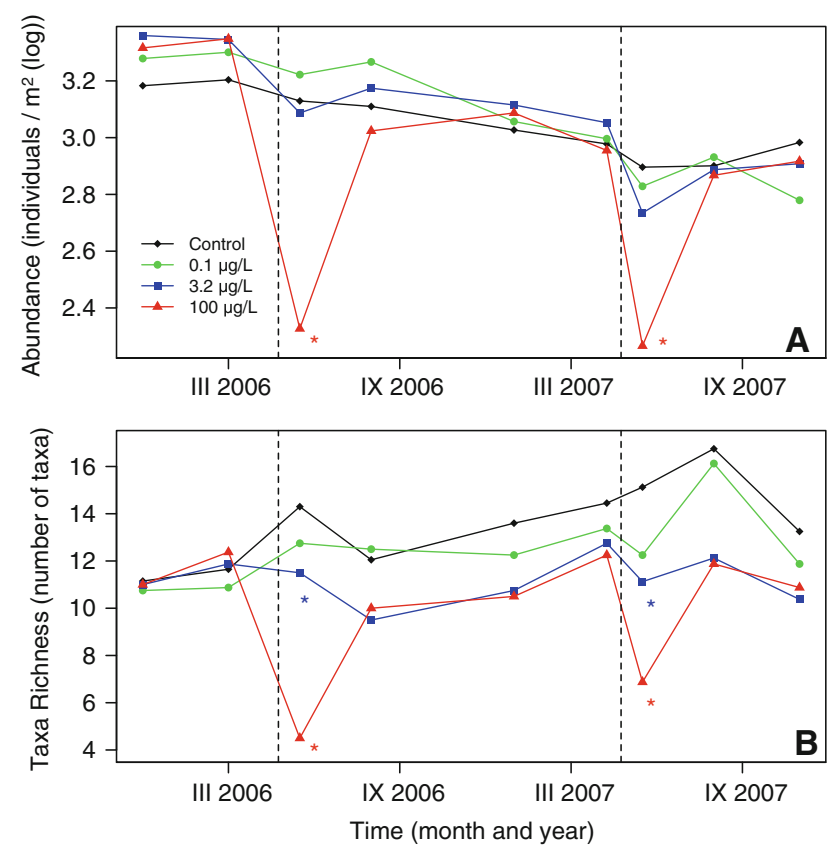

Fig. 1 Abundance (a) and taxa richness (b) of aquatic macroinvertebrates $(\log (x+1)$-transformed number of individuals per square metre and number of taxa, respectively). Asterisks indicate significant $(P<0.05$, ANOVA, Games-Howell post hoc tests) differences from the controls. Vertical dashed lines show contamination events basis of these traits revealed that nonsensitive multivoltine species only experienced transient effects of the toxicant at the highest concentration of thiacloprid (100 $\mu \mathrm{g} / \mathrm{l}$; Fig. 2a). For sensitive multivoltine species, transient effects were observed at the concentration of $3.3 \mu \mathrm{g} / \mathrm{l}$ (Fig. 2b). Nonsensitive univoltine species showed transient effects at $100 \mu \mathrm{g} / \mathrm{l}$ (Fig. 2c). Only sensitive univoltine species showed long-term effects at the lowest tested concentration of $0.1 \mu \mathrm{g} / \mathrm{l}$ (Fig. 2d). The five species characterised by this trait combination did not exhibit significant recovery within the duration of the experiment.

In order to compare variability within the trait-based groups with variability in the separate species, we calculated the coefficients of variation $(\mathrm{CV})$ for the sensitive univoltine species for each of the experimental treatments. Comparison of the CVs derived for the trait-based groups with the variability of single species revealed much lower variability for the trait-based groups than for the individual species. The average CVs for the entire experimental period for the control, low, medium, and high concentrations of thiacloprid were 58, 87, 186, and 48.57 for the traitbased group of sensitive univoltine species, and 160, 223, 435, and 165.3 for the independently considered species, respectively.

\section{Community effect measures-PRC}

versus $S P E A R_{\text {mesocosm }}$

The effect of thiacloprid on community structure was investigated with the PRC method and the index developed here, SPEAR mesocosm. PRC has been developed especially for the analysis of data obtained in experimental studies of the responses of communities to toxicants and has become a widely used method for analysing the effect in mesocosms (e.g. deJong et al. 2008). For the data presented here, this method, combined with separate RDAs for each time point and followed by Monte Carlo permutation tests, identified community responses to thiacloprid at concentrations of 3.2 and $100 \mu \mathrm{g} / \mathrm{l}$ (Fig. 3a). At these two concentrations, an effect was observed for 3 months after the first contamination. After the second contamination, the effect was observed until the end of the test period (for 7 months) with the $100 \mu \mathrm{g} / \mathrm{l}$ treatment, whereas for $3 \mu \mathrm{g} / \mathrm{l}$, the effect was again observed for 3 months (Fig. 3a).

The index SPEAR $R_{\text {mesocosm }}$ identified long-term community responses to thiacloprid at all concentrations tested, which included the lowest concentration of $0.1 \mu \mathrm{g} / 1$ (Fig. 3b). For this method, the effect was defined as the proportion of long-living, sensitive taxa among the entire community (for details, see Methods). This change in community structure could be identified for the entire duration of the experiment, which included the period of around 1 year after the first contamination event (Fig. 3b). 

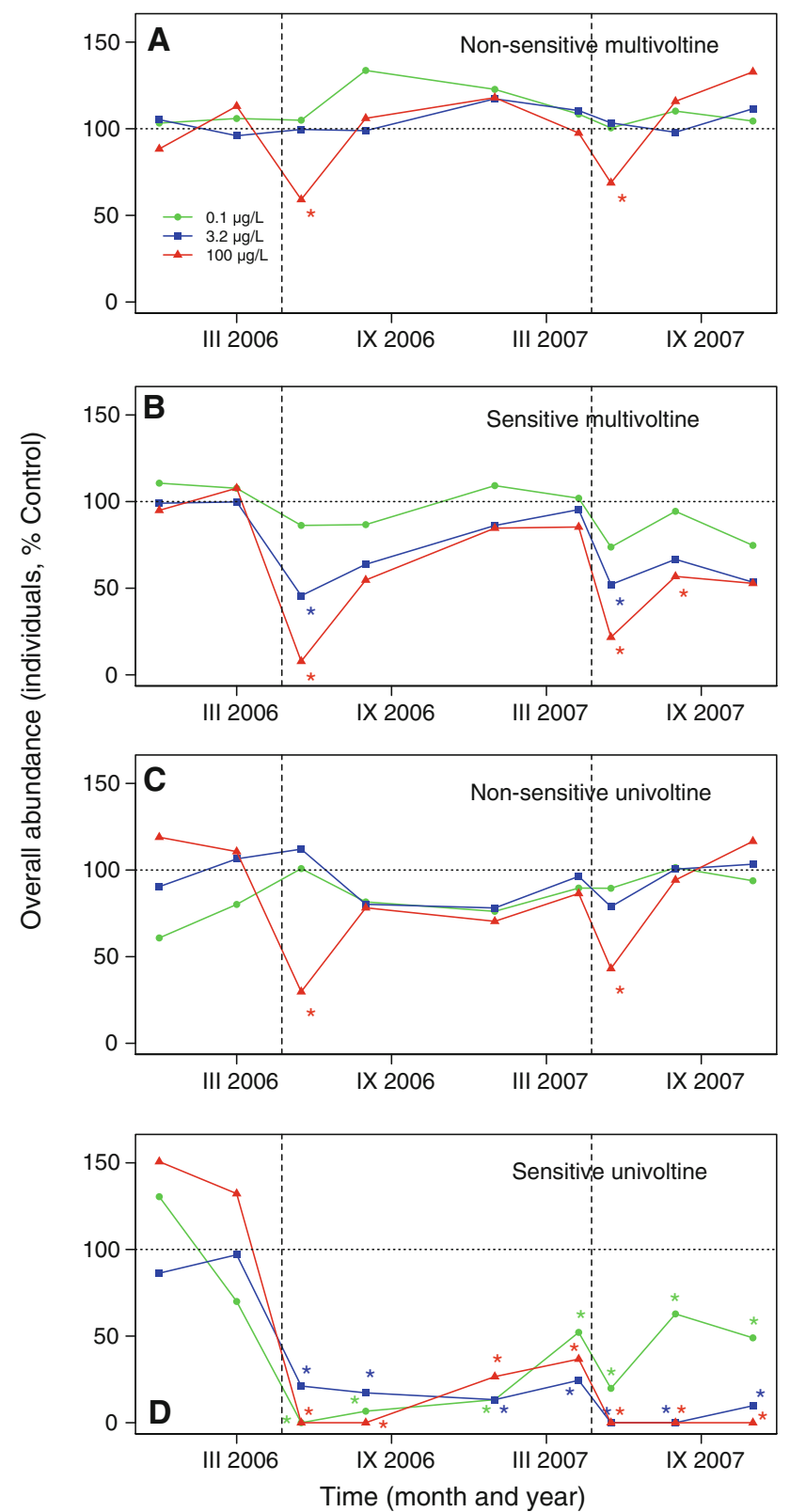

Fig. 2 Abundance as a percentage of the control values for the four trait-based groups of aquatic macroinvertebrates: nonsensitive multivoltine (a), sensitive multivoltine (b), non-sensitive univoltine (c), and sensitive univoltine (d). Asterisks indicate significant $(P<0.05$, ANOVA, Games-Howell post-hoc tests) differences from the controls. Vertical dashed lines show contamination events

Classification of sensitivity for most species was obtained from the $S P E A R_{\text {pesticide }}$ database that is not substance specific. According to specific sensitivity information specifically available for thiacloprid we adopted this classification for two species as outlined in the methods. We investigated how the calculation of SPEAR $R_{\text {mesocosm }}$ changes if the substance specific information were not included. Using only the general toxicity information differences between control and lowest concentration were still obvious but not significant any more.

Comparison of the PRC and SPEAR $R_{\text {mesocosm }}$ methods showed that the latter method was clearly more able to identify effects at low concentrations, as well as long-term effects. The LOECs and NOECs derived by these two methods differed considerably. Regarding the acute LOEC, SPEAR $R_{\text {mesocosm }}$ showed effects at one concentration step lower than PRC (factor 30). Regarding the chronic LOEC 1 year after contamination, SPEAR $R_{\text {mesocosm }}$ showed effects at there concentration steps lower than PRC (factor 1000) (Table 3).

Interestingly, the species classified by PRC as most affected (the four species having bk-values higher than 2, Fig. 3a) include only one sensitive univoltine species (Limnephilus lunatus). The other species identified as sensitive by PRC are showing effects only at the high concentrations and for a short period of time. This indicates a basic difference between PRC and SPEAR. The PRC calculates the strength of effects over the entire period analysed and for all concentrations. Hence, also short-term effects at high concentrations may result in a response of the PRC values. The response of PRC is not necessarily based on long-term effects at low concentrations. In contrast, SPEAR is grouping species with known high sensitivity and low recovery potential. As a consequence the SPEAR approach is pinpointing long-term community effects at low concentrations that are missed by the PRC approach because of the high variability of such effects.

Population viability, stress, and sensitivity to the toxicant

\section{Population stress determines sensitivity}

Long-term development of the populations of all sensitive univoltine species was investigated in the control streams. From May 2006 until November 2007 the abundance of two species was found to have declined by a factor of approximately -1.5 (Ephemera vulgata and Nemoura cinerea). In the same period, the abundance of three species increased on average by a factor of approximately 2.5 (Atherix sp., Hydropsyche angustipennis, and Limnephilus lunatus).

Species characterised by an increase of population density in control mesocosms showed an effect on survival of approximately $50 \%$ in mesocosms exposed $0.1 \mu \mathrm{g} / \mathrm{l}$ thiacloprid over the two-season period. In contrast, species that were characterised by a decrease of population density in control mesocosms showed complete extinction at $0.1 \mu \mathrm{g} / \mathrm{l}$ thiacloprid (Fig. 4). At higher concentrations, no link between long-term mortality under control conditions and the strength of the effect of thiacloprid could be established, because most of these sensitive species were eliminated completely at the higher concentrations of 3.2 and $100 \mu \mathrm{g} / \mathrm{l}$. 
Fig. 3 Principal response curves (PRC) (a) and the $S P E A R_{\text {mesocosm }}$ index (b), which indicate the proportion of sensitive taxa, are shown as a percentage of the control values. The large black asterisks at the top of the graphs indicate significant $(P<0.05)$ effects of the toxicant in the whole model (all concentrations) as tested by Monte Carlo permutation tests followed by RDA for PRC (a) and ANOVA and GamesHowell post hoc tests for SPEAR $_{\text {mesocosm }}(\mathbf{b})$. The small coloured asterisks indicate significant $(P<0.05)$ effects at particular concentrations tested by the same methods
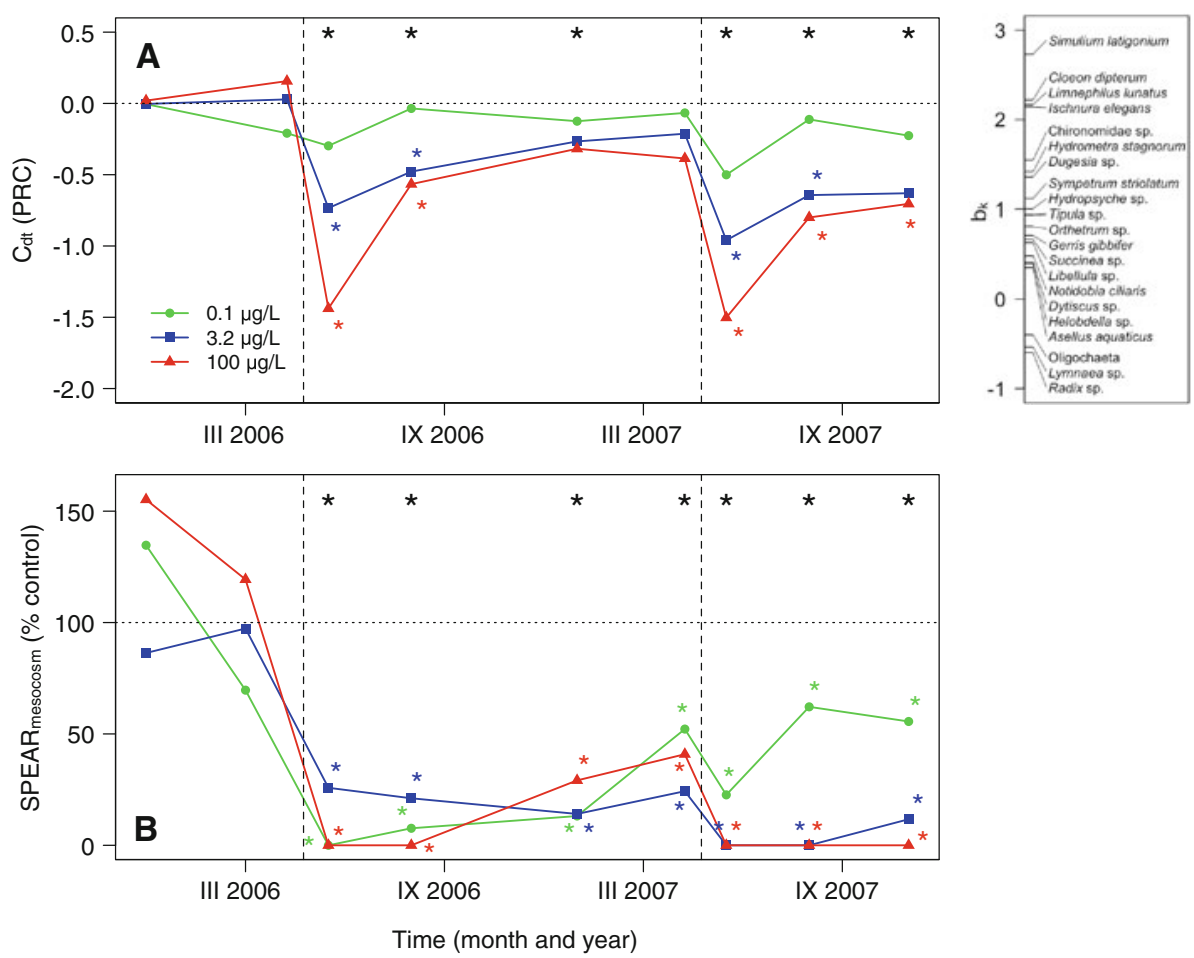

Table 3 Lowest-observable-effect concentrations (LOEC) and no-observable-effect concentrations (NOEC) derived by Monte Carlo permutation tests followed by redundancy analyses (RDA) and by by ANOVA followed by the Games-Howell post hoc test for the adapted SPEAR $_{\text {mesocosm }}$ index (SPEAR) (see also Fig. 3)

\begin{tabular}{|c|c|c|c|c|}
\hline \multirow{2}{*}{$\begin{array}{l}\text { Time after } \\
\text { contamination (weeks) }\end{array}$} & \multicolumn{2}{|c|}{ LOEC $(\mu \mathrm{g} / \mathrm{l})$} & \multicolumn{2}{|c|}{ NOEC $(\mu \mathrm{g} / \mathrm{l})$} \\
\hline & RDA & SPEAR & RDA & SPEAR \\
\hline \multicolumn{5}{|l|}{ First-year contamination } \\
\hline 2 & 3.2 & $<0.1$ & 0.1 & $<0.1$ \\
\hline 13 & 3.2 & $<0.1$ & 0.1 & $<0.1$ \\
\hline 34 & ND & $<0.1$ & ND & $<0.1$ \\
\hline 48 & NS & $<0.1$ & NS & $<0.1$ \\
\hline \multicolumn{5}{|c|}{ Second-year contamination } \\
\hline 2 & 3.2 & $<0.1$ & 0.1 & $<0.1$ \\
\hline 8 & 3.2 & $<0.1$ & 0.1 & $<0.1$ \\
\hline 38 & 100 & $<0.1$ & 3.2 & $<0.1$ \\
\hline
\end{tabular}

$N D$ not determined; LOEC and NOEC cannot be determined precisely, because a significant effect was only found for all concentrations together (complete models), but no significant effect was found for any of the concentrations analysed separately (see Fig. 3)

$N S$ not significant; no significant $(P<0.05)$ effects were detected

\section{Discussion}

Using traits to link exposure and effect

The LOEC for acute community effects revealed by $S P E A R_{\text {mesocosm }}$ was a factor of 30 lower than that revealed by PRC. For chronic effects, the LOEC revealed by

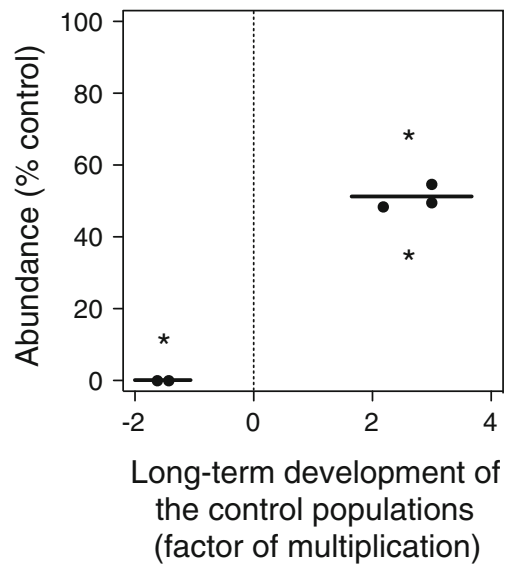

Fig. 4 Effect of thiacloprid at $0.1 \mu \mathrm{g} / \mathrm{l}$ on species that were characterised by decline or increase of abundance in control mesocosms (right and left of the dashed line, respectively) over the 2 years after the first contamination (between-year change of abundance, factor of multiplication). The horizontal lines indicate the mean values for the two groups (i.e. decline and increase). Asterisks above the line indicate the difference from the control, whereas the asterisk below the line indicates the difference between the two groups $(P<0.05$, one-sample $t$-test $)$

SPEAR mesocosm $_{\text {was a factor of } 1,000 \text { lower than that }}$ revealed by PRC. We suggest that the reason for this striking difference between the two methods is the variation of species abundance in such complex systems. Similar to natural communities, mesocosm communities are shaped by a multitude of environmental parameters that characterise the habitat and the biotic interactions present 
in the community. Firstly, environmental parameters that shape the composition of the community were not identical in the different replicates. Factors such as the velocity of the current and the structures provided by plants will have been slightly different. Secondly, biotic interactions may have been different between replicates as a result of differences in environmental parameters and stochastic processes, for example, those that occur within the process of colonisation. Hence, communities within each mesocosm were unique to a certain degree, similar to natural communities, which resulted in considerable inter-replicate variation (Sanderson et al. 2009). Multivariate analyses lose power in the identification of statistical links when variation is high. The description of biological communities in terms of traits provides a focused and simplified description of the community (McGill et al. 2006). The trait-based grouping of species according to the SPEAR approach aggregates those species that are affected by the toxicant. Applying this a priori ecotoxicological knowledge species were aggregated into trait-based groups that reflected stressor-specific vulnerability of populations to toxicant exposure. This reduces inter-replicate variation that is not related to toxicant effects and enables to better link exposure and effect (Liess and von der Ohe 2005). This was shown herein by finding that the CVs were lower for the trait groups than for the individual taxa, a fact that explains why SPEAR is identifying long-term effects at low concentrations in contrast to the PRC approach. The successful grouping is based on existing knowledge about traits that are sensitive to pesticides with this knowledge being combined in an a priori approach similar to the one used to identify the effects of insecticides on communities in the field (Liess and von der Ohe 2005). The single traits that reflected sensitivity of populations to toxicant exposure were the inability to (i) recover from a recurring stressor, which is linked to a long generation time (Barnthouse 2004) and (ii) survive toxicant exposure, which is linked to high toxicological sensitivity, as quantified by (Wogram and Liess 2001) updated (von der Ohe and Liess 2004) and specified for thiacloprid (Beketov and Liess 2008).

Stress influencing magnitude of toxicant effect

Chronic effects of thiacloprid on the five long-living sensitive species identified in the microcosm occurred at $0.1 \mu \mathrm{g} / \mathrm{l}$. These chronic effects caused by thiacloprid occurred at a concentration that was 70 times below the lowest known acute LC50 for this toxicant (Beketov and Liess 2008). Such an acute to chronic ratio (ACR) is well below that which is found generally for fish (10.5), daphnids (7.0), and algae (5.4) (Ahlers et al. 2006). In addition to this low concentration at which an effect could be identified, we observed even stronger effects when populations were stressed, as indicated by the long-term decline in abundance of stressed species in control streams. We assume that these results are associated with individual stress within the mesocosms. The mesocosms were designed to include levels of stress that reflect those that occur in the field through competition and predation and are typical for ageing communities. This was achieved by the incorporation of a long precontamination period of 2 years. Hence, we assume that competitive interaction between conspecifics and controphics for food exerted stress on individuals (Schoener 1983). In addition, predation pressure is expected to have occurred because several predatory insects were present in the mesocosm (Peckarsky and McIntosh 1998). The combined effects of predation, intimidation by predators, and competition for food can exert pronounced stress and significantly reduce individual fitness (Bolnick and Preisser 2005; Beketov and Liess 2007).

It has often been stated that stressed organisms are more vulnerable to toxicants. For example, in test systems, abiotic stressors such as high temperature (Fisher and Wadleigh 1985; Song et al. 1997; Lydy et al. 1999) and a deficiency of food (Pieters et al. 2005) were found to increase the sensitivity of macroinvertebrates to insecticides by a factor of from 2 to 10 . UV radiation in conjunction with food deficiency increased sensitivity to copper by a factor of more than 30 (Liess et al. 2001). In addition, biotic stressors such as competition (Liess 2002; Beketov and Liess 2005) and predation pressure (Schulz and Dabrowski 2001; Beketov and Liess 2006) increased vulnerability to toxicants. Furthermore, field investigations have revealed that stress in combination with exposure to toxicants might exert synergistic effects on the viability of populations. A decline in amphibians was linked to the combined effect of parasites and atrazine (Rohr et al. 2008) and the absence of amphipods in a contaminated bay in Antarctica was linked to the combined effect of UV radiation and copper (Duquesne and Liess 2003).

In the light of these observations we suggest to differentiate between "toxicological sensitivity" and "context sensitivity" to account for the increase in the sensitivity of organisms to toxicants. We define toxicological sensitivity as the sensitivity of a species to a toxicant under optimal environmental conditions for the respective species. In general, such conditions are achieved in standard test systems, which are characterised by low mortality under control conditions. Such optimal conditions will also occur in the natural environment, but rather as an exception. We define context sensitivity to account for the altered sensitivity in the context of environmental conditions that includes stress. Mortality or sublethal stress within the natural context are caused by competition (Hülsmann and Weiler 2000; Hülsmann 2001), predation (Lampert et al. 1986), and unfavourable environmental conditions 
(Baillieul et al. 1996). Additionally, sensitivity in the context of environmental conditions includes processes that reduce sensitivity. This is for example selection of tolerant/resistant strains or enhanced metabolic performances associated to previous exposure to toxicants. We conclude that the environmental context determines species sensitivity to a toxicant.

Prospective risk assessment with $S P E A R_{\text {mesocosm }}$

We suggest using the SPEAR $R_{\text {mesocosm }}$ approach in complement to the PRC analyses in order to obtain a comprehensive assessment of the toxicant induced community effect. The PRC approach delivers an overall assessment of community effects identifying sensitive species and also species benefitting from contamination. The downside of the approach is a weakness in identifying effects on species showing a high variation in abundance within the test-systems. In contrast, the trait-based grouping of species in accordance with the SPEAR approach aggregates species that are affected by the toxicant and by this reduces inter-replicate variation. Hence, the description of biological communities in terms of traits provides a focused and simplified identification of sensitive species. If available, information on the specific sensitivity of investigated organisms should be included to obtain the best possible species classification on sensitivity. However, if such information are not available, already the standard classification used for the SPEAR pesticide $_{\text {approach (Liess and }}$ von der Ohe 2005) allows an assessment of toxicant induced community effects.

Within the current investigation we have used stream mesocosms to apply the approach. We argue that the same approach can also be used for pond mesocosms as the traits used to calculate $S P E A R_{\text {mesocosm }}$ are also relevant to describe effect and recovery of lentic organisms. For toxicological sensitivity it was shown that no difference in SSD's are apparent when comparing lentic and lotic species (Maltby et al. 2005). Also the relevance of life-cycle traits for the duration of recovery is evident. However, it may be necessary to adopt thresholds of life-cycle traits according the community investigated. For example, communities consisting only from short-living species will show faster recovery from toxicant induced effects compared to communities with a high proportion of long-living species.

The effects of toxicants in the field have been described using trait modalities and linked to the classes of water quality defined by the water framework directive (WFD) (Beketov et al. 2009). The effects observed in mesocosms can also be related to the quality classes defined by the WFD. Effects that are detected in mesocosms can be translated directly to effects predicted for the field by comparing the ratio of species at risk, independent of the geographic region in question (Liess et al. 2008). However, to enable a sound effect assessment mesocosms should host a community that includes organisms that are (i) toxicologically sensitive to realistically assess the ability of the community to detect effects and (ii) sufficiently long-lived to realistically assess the time required for the community to recover.

\section{Conclusion}

The trait-based identification of effects of low levels of toxicants in mesocosm communities is possible. When trait modalities rather than species are assessed within a community, it becomes possible to predict effects in the field across taxa, environmental conditions, and geographic borders. The SPEAR $R_{\text {mesocosm }}$ approach facilitates the interpretation of results within the framework of risk assessment, because the results can be linked directly to the distribution of traits in the field.

Acknowledgments The study was supported by the European Union (Project INTERACT, Marie Curie IIF contract no. MIF1CT-2006-021860) and the Helmholtz Association of German Research Centres (Project ECOLINK, HRJRG-025). We thank two anonymous reviewers for many constructive suggestions.

Open Access This article is distributed under the terms of the Creative Commons Attribution Noncommercial License which permits any noncommercial use, distribution, and reproduction in any medium, provided the original author(s) and source are credited.

\section{Appendix}

See Table 4.

Table 4 List of the taxa recorded in the mesocosm system

\begin{tabular}{ll}
\hline Taxa & Order/class \\
\hline Non-sensitive multivoltine taxa & \\
Asellus aquaticus & Isopoda \\
Dytiscidae & Coleoptera \\
Dugesia sp. & Tricladida \\
Erpobdella sp. & Arhynchobdellida (Hirudinea) \\
Gammarus sp. & Amphipoda \\
Gerris gibbifer & Heteroptera \\
Haliplus sp. & Coleoptera \\
Helobdella sp. & Rhynchobdellida (Hirudinea) \\
Hydracarina & Acariformes (Arachnida) \\
Hydrometra stagnorum & Heteroptera \\
Hydrophilidae & Coleoptera \\
Notonecta glauca & Heteroptera \\
Oligochaeta & Oligochaeta \\
Succinea sp. & Succineoidea (Gastropoda) \\
\hline
\end{tabular}


Table 4 continued

\begin{tabular}{|c|c|}
\hline Taxa & Order/class \\
\hline \multicolumn{2}{|l|}{ Sensitive multivoltine taxa } \\
\hline Baetis macani & Ephemeroptera \\
\hline Chironomidae & Diptera \\
\hline Cloeon dipterum & Ephemeroptera \\
\hline Simulium latigonium & Diptera \\
\hline Tipula sp. & Diptera \\
\hline \multicolumn{2}{|l|}{ Non-sensitive univoltine taxa } \\
\hline Aeshna sp. & Odonata \\
\hline Ischnura elegans & Odonata \\
\hline Leucorrhinia sp. & Odonata \\
\hline Libellula quadrimaculata & Odonata \\
\hline Lymnaea sp. & Lymnaeoidea (Gastropoda) \\
\hline 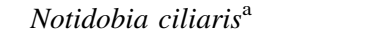 & Trichoptera \\
\hline Orthetrum coerulescens & Odonata \\
\hline Planorbis sp. & Planorboidea (Gastropoda) \\
\hline Radix sp. & Lymnaeoidea (Gastropoda) \\
\hline Sialis sp. & Megaloptera \\
\hline Sympetrum striolatum & Odonata \\
\hline \multicolumn{2}{|l|}{ Sensitive univotine taxa } \\
\hline Atherix sp. & Diptera \\
\hline Ephemera vulgata ${ }^{\mathrm{b}}$ & Ephemeroptera \\
\hline Hydropsyche angustipennis & Trichoptera \\
\hline Limnephilus lunatus & Trichoptera \\
\hline Nemoura cinerea & Plecoptera \\
\hline \multicolumn{2}{|c|}{ Rare taxa, group was not defined ${ }^{c}$} \\
\hline Agrypnia varia & Trichoptera \\
\hline Athripsodes cinereus & Trichoptera \\
\hline Cloeon simile & Ephemeroptera \\
\hline Culex pipiens & Diptera \\
\hline Culex territans & Diptera \\
\hline Enallagma cyathigerum & Odonata \\
\hline Helophorus sp. & Coleoptera \\
\hline
\end{tabular}

a Although this species is known to be sensitive to thiacloprid (Beketov and Liess 2008), it was considered herein to be insensitive because it emerged before and oviposited after the contamination (i.e. no aquatic stage was present during contamination) and demonstrated no dose response

b This species is semivoltine. For an explanation of classification, see the text (Methods)

c These taxa were considered to be extremely rare and were omitted from the analyses because they were found in no more than two streams and on no more than one occasion

\section{References}

Ahlers J, Riedhammer C et al (2006) Acute to chronic ratios in aquatic toxicity - variation across trophic levels and relationship with chemical structure. Environ Toxicol Chem 25:2937-2945
Ashauer R (in revision) Post-ozonation in a municipal 1 wastewater treatment plant improves water quality in receiving stream as indicated by the abundance of species at risk. Ecotoxicology

Baillieul M, Selens M, Blust R (1996) Scope for growth and fitness of Daphnia magna in salinity-stressed conditions. Funct Ecol 10: 227-233

Barnthouse LW (2004) Quantifying population recovery rates for ecological risk assessment. Environ Toxicol Chem 23:500-508

Beketov MA, Liess M (2005) Acute contamination with esfenvalerate and food limitation: chronic effects on the mayfly, Cloeon dipterum. Environ Toxicol Chem 24:1281-1286

Beketov MA, Liess M (2006) The influence of predation on the chronic response of Artemia sp. populations to a toxicant. J Appl Ecol 43:1069-1074

Beketov MA, Liess M (2007) Predation risk perception and food scarcity induce alterations of life-cycle traits of the mosquito Culex pipiens. Ecol Entomol 32:405-410

Beketov MA, Liess M (2008) Acute and delayed effects of the neonicotinoid insecticide thiacloprid on seven freshwater arthropods. Environ Toxicol Chem 27:461-470

Beketov M, Schäfer RB, Marwitz A, Paschke A, Liess M (2008) Long-term stream invertebrate community alterations induced by the insecticide thiacloprid: effect concentrations and recovery dynamics. Sci Total Environ 405:96-108

Beketov MA, Foit K, Schäfer RB, Sacchi A, Capri E, Biggs J, Wells C, Liess M (2009) SPEAR indicates pesticide effects in streams - comparative use of species- and family-level biomonitoring data. Environ Pollut 157:1841-1848

Berenzen N, Schulz R, Liess M (2001) Effects of chronic ammonium and nitrite contamination on the macroinvertebrate community in running water microcosms. Water Res 35:3478-3482

Bolnick DI, Preisser EL (2005) Resource competition modifies the strength of trait-mediated predator-prey interactions: a metaanalysis. Ecology 86:2771-2779

deJong FMW, Brock TCM, Foekema EM (2008) Guidance for summarizing and evaluating aquatic micro- and mesocosm studies. RIVM Report 601506009/2008

Doledec S, Statzner B (2008) Invertebrate traits for the biomonitoring of large European rivers: an assessment of specific types of human impact. Freshw Biol 53:617-634

Duquesne S, Liess M (2003) Increased sensitivity of the macroinvertebrate Paramorea walkeri to heavy-metal contamination in the presence of solar UV radiation in Antarctic shoreline waters. Mar Ecol Prog Ser 255:183-191

Fisher SW, Wadleigh RW (1985) Effects of temperature on the acute toxicity and uptake of lindane by Chironomus-riparius (meigen) (diptera, chironomidae). J Econ Entomol 78:1222-1226

Heugens E, Hendriks A, Dekker T, van Straalen NM, Admiraal W (2001) A review of the effects of multiple stressors on aquatic organisms and analysis of uncertainty factors for use in risk assessment. Crit Rev Toxicol 31:247-284

Hülsmann S (2001) Reproductive potential of Daphnia galeata in relation to food conditions: implications of a changing sizestructure of the population. Hydrobiologia 442:241-252

Hülsmann S, Weiler W (2000) Adult, not juvenile mortality as a major reason for the midsummer decline of a Daphnia population. J Plankton Res 22:151-168

Lampert W, Fleckner H, Rai H, Taylor BE (1986) Phytoplankton control by grazing zooplankton: a study on the clear-water phase. Limnol Oceanogr 31:478-490

Leps J, Smilauer P (2003) Multivariate analysis of ecological data using CANOCO. University Press, Cambridge

Liess M (2002) Population response to toxicants is altered by intraspecific interaction. Environ Toxicol Chem 21:138-142 
Liess M, Schulz R (1999) Linking insecticide contamination and population response in an agricultural stream. Environ Toxicol Chem 18:1948-1955

Liess M, von der Ohe PC (2005) Analyzing effects of pesticides on invertebrate communities in streams. Environ Toxicol Chem 24:954-965

Liess M, Schulz R, Liess MH-D, Rother B, Kreuzig R (1999) Determination of insecticide contamination in agricultural headwater streams. Water Res 33:239-247

Liess M, Champeau O, Riddle M, Schulz R, Duquesne S (2001a) Combined effects of ultraviolett-B radiation and food shortage on the sensitivity of the Antarctic amphipod Paramoera walkeri to copper. Environ Toxicol Chem 20:2088-2092

Liess M, Schulz R, Berenzen N, Nanko-Drees J, Wogram J (2001) Pesticide contamination and macroinvertebrate communities in running waters in agricultural areas. UBA Texte 65. Umweltbundesamt, Berlin

Liess M, Schäfer RB, Schriever CA (2008) The footprint of pesticide stress in communities-species traits reveal community effects of toxicants. Sci Total Environ 406:484-490

Lydy MJ, Belden JB, Ternes MA (1999) Effects of temperature on the toxicity of M-parathion, chlorpyrifos, and pentachlorobenzene to Chironomus tentans. Arch Environ Contam Toxicol 37:542-547

Maltby L, Blake N, Brook TCM, van den Brinck PJ (2005) Insecticide species sensitivity distributions: importance of test species selection and relevance to aquatic ecosystems. Environ Toxicol Chem 24:379-388

McGill BJ, Enquist BJ, Weiher E, Westoby M (2006) Rebuilding community ecology from functional traits. Trends Ecol Evol 21:178-185

Menezes S, Baird DJ, Soares A (2010) Beyond taxonomy: a review of macroinvertebrate trait-based community descriptors as tools for freshwater biomonitoring. J Appl Ecol 47:711-719

Mommaerts V, Reynders S, Boulet J, Besard L, Sterk G, Smagghe G (2010) Risk assessment for side-effects of neonicotinoids against bumblebees with and without impairing foraging behavior. Ecotoxicology 19:207-215

Peckarsky BL, McIntosh AR (1998) Fitness and community consequences of avoiding multiple predators. Oecologia 113:565-567

Peru N, Doledec S (2010) From compositional to functional biodiversity metrics in bioassessment: a case study using stream macroinvertebrate communities. Ecol Indic 10:1025-1036

Peterson CH, Rice SD, Short JW, Esler D, Bodkin JL, Ballachey JE, Irons DB (2003) Long-term ecosystem response to the Exxon Valdez oil spill. Science 302:2082-2086

Pieters BJ, Paschke A, Reynaldi S, Kraak MHS, Admiraal W, Liess $M$ (2005) Influence of food limitation on the effects of Fenvalerate pulse exposure on the life history and population growth rate of Daphnia magna. Environ Toxicol Chem 24: 2254-2259

Rohr JR, Schotthoefer AM, Raffel TR, Carrick HJ, Halstead N, Hoverman JT, Johnson CM, Johnson LB, Lieske C, Piwoni MD, Schoff PK, Beasly VR et al (2008) Agrochemicals increase trematode infections in a declining amphibian species. Nature 455:1235-1239

Sanderson H, Laird B, Brain R, Wilson CJ, Solomon KR (2009) Detectability of fifteen aquatic micro/mesocosms. Ecotoxicology 18:838-845
Schäfer RB, Caquet T, Siimes K, Mueller R, Lagadic L, Liess M (2007) Effects of pesticides on community structure and ecosystem functions in agricultural streams of three biogeographical regions in Europe. Sci Total Environ 382:272-285

Schäfer R, Paschke A, Liess M (2008) Aquatic passive sampling of a short-term thiacloprid pulse with the Chemcatcher. Impact of biofouling and use of a diffusion-limiting membrane on the sampling rate. J Chromatogr A 1230:1-6

Schoener TW (1983) Field experiments on interspecific competition. Am Nat 122:240-285

Schulz R, Dabrowski JM (2001) Combined effects of predatory fish and sublethal pesticide contamination on the behaviour and mortality of mayfly nymphs. Environ Toxicol Chem 20:2537-2543

Sherratt TN, Roberts G, Williams P, Whitefield M, Biggs J, Shillabeer N, Maund SJ (1999) A life-history approach to predicting the recovery of aquatic invertebrate populations after exposure to xenobiotic chemicals. Environ Toxicol Chem 18:2512-2518

Song MY, Stark JD, Brown JJ (1997) Comparative toxicity of four insecticides, including imidacloprid and tebufenozide, to four aquatic arthropods. Environ Toxicol Chem 16:2494-2500

Southwood TRE (1988) Tactics, strategies and templets. Oikos 52: $3-18$

Statzner B, Beche LA (2010) Can biological invertebrate traits resolve effects of multiple stressors on running water ecosystems? Freshw Biol 55:80-119

Townsend CR, Hildrew AG (1994) Species traits in relation to a habitat templet for river systems. Freshw Biol 31:265-275

U.S. Environmental Protection Agency (USEPA) (2003) Pesticide fact sheet, thiacloprid. Office of Prevention, Pesticides and Toxic Substances, Washington, DC, 13 pp

Usseglio-Polatera P, Bournaud M, Richoux P, Tachet H (2000) Biological and ecological traits of benthic freshwater macroinvertebrates: relationships and definition of groups with similar traits. Freshw Biol 43:175-205

Van den Brink PJ, Ter Braak CJF (1999) Principal response curves: analysis of time-dependent multivariate responses of biological community to stress. Environ Toxicol Chem 18:138-148

Van der Geest HG, Soppe WJ, Greve GD (2002) Combined effects of lowered oxygen and toxicants (copper and diazinon) on the mayfly Ephoron virgo. Environ Toxicol Chem 21:431-436

Van Urk G, Kerkum F, van Leeuwen CJ (1993) Insects and insecticides in the lower Rhine. Water Res 27:205-213

von der Ohe P, Liess M (2004) Relative sensitivity distribution (RSD) of aquatic invertebrates to organic and metal compounds. Environ Toxicol Chem 23:150-156

Wildgust MA, Jones MB (1998) Salinity change and the toxicity of the free cadmium ion $[\mathrm{Cd}-(\mathrm{aq})(2+)]$ to Neomysis integer (Crustacea: Mysidacea). Aquat Toxicol 41:187-192

Wogram J, Liess M (2001) Rank ordering of macroinvertebrate species sensitivity to toxic compounds by comparison with that of Daphnia magna. Bull Environ Contam Toxicol 67:360-367

Yokoyama A, Ohtsu K, Iwafune T, Nagai T, Ishihara S, Kobara Y, Horio T, Endo S (2009) A useful new insecticide bioassay using first-instar larvae of a net-spinning caddisfly, Cheumatopsyche brevilineata (Trichoptera: Hydropsychidae). J Pest Sci 34(1):13-20. doi:10.1584/jpestics.G08-26

Zar JH (1996) Biostatistical analysis. Prentice-Hall, Englewood Cliffs, New York 